\title{
Test Taking Strategies Instruction and Iranian EFL Learners' Performance on International Language Tests
}

\author{
Mitra Ghabelju (Corresponding author) \\ Guilan University, Iran \\ E-mail: mitraghabeljou@gmail.com
}

Received: 28-07- 2012

doi:10.7575/ijalel.v.2n.1p.1
Accepted: 17-08- 2012

Published: 01-01- 2013

\begin{abstract}
This study examined the effects of test-taking strategies instruction on Iranian foreign language learners' performance on international English language tests namely IELTS and TOEFL. Based on IELTS pre- test, sixty intermediate participants of both genders from different fields of study including computer engineering, electrical engineering, mechanical engineering, accountancy, and chemical engineering were selected for this study. Then they were randomly divided into two groups (one control and one experimental each consisting of 30 participants). The experimental group was taught general and specific test-taking strategies, while the control group did not receive any specific instructions on test taking strategies. After twelve sessions of treatment for the experimental group and placebo for the control group, both groups took part in IELTS and TOEFL post- tests. While the two groups were homogeneous in terms of their language proficiency at the beginning of the study, the results of independent samples $\mathrm{T}$ - test showed that the experimental group significantly outperformed the control group on both post-tests. The findings suggest that there is a positive relationship between test-performance and test taking strategies. The findings also suggest support for training EFL classroom teachers to provide instruction in test-taking strategy.
\end{abstract}

Keywords: test taking strategies, international English language tests

\section{Introduction}

Language tests are one of the most widely used evaluation tools in language testing and provide scores that are used for assessing test-takers' language ability, decision making and screening purposes (Rezaee, 2006). Among the many personal factors that affect test scores, is the way test-takers approach the examination, i.e., the strategies they use while taking a test (Nunan, 1999). Together with individual differences as well as situational and social factors, knowledge of test-taking strategies is one of the factors that are believed to determine the variable outcome of language learning.

Very few attempts have been made to elucidate the impact of teaching test taking strategies on the performance of intermediate EFL learners on the Academic Reading Module of IELTS or TOEFL. Therefore, the researcher tried to investigate the effect of test taking strategies instruction on test performance of the EFL learners.

The purpose of this investigation is to determine whether knowledge of test-taking strategies has any impact on the performance of intermediate EFL learners on the Academic Reading Module of IELTS tests.

\section{Research questions}

1) Is there any significant difference between the performance of Iranian intermediate English as Foreign Language (EFL) learners who received instruction on test-taking strategies and the performance of those who only received conventional instructions on the Academic Reading Module of IELTS?

2) Are learners who receive instructions on test-taking strategies for the Academic Reading Module of IELTS able to apply these strategies equally well in performing on the TOEFL?

\section{Method}

3.1 The Design of the Study

The design of this study was quasi-experimental and had three basic characteristics:

1) Pre- test (academic sample of IELTS).

2) Treatment (Strategy and Comprehension - based training session).

3) Post test (reading samples of IELTS and TOEFL)

\subsection{Participants}

This study was conducted with a total number of 160 Iranian learners studying at Shahid Beheshti University, Tehran (SBUT) and also 120 participants from the IELTS Center of Tehran (ICT). These students were administered an 
Academic Module IELTS test and, ultimately, 60 of the original 280 test-takers were selected to participate in this study.

\subsection{Instruments and Materials}

\section{The following instruments were used for the present study:}

1. Listening Module of the IELTS 2. Academic Reading Module of the IELTS 3.Writing Module of the IELTS (Cambridge IELTS, 2008) 4. Reading Section of the TOEFL PBT (Barron's TOEFL preparation book, 2011).

\subsection{Data Collection Procedure}

For data collection in this study, a sample of an Academic Module IELTS exam as the pre-test and a sample Academic Reading Module of IELTS as the post-test were utilized. These were administered to 280 participants at ICT and SBUT facilities. After data collection, from among 81 intermediates, 60 were deemed homogeneous in their terms of language ability and were randomly assigned to two IELTS preparation classes. The first group (Group A: experimental group) attended strategy-based training sessions during which they received specific test-taking strategies and general testtaking strategies, and the second group (Group B: control group) attended comprehension-based training sessions. After the training sessions were over, participants of the two groups were exposed to a sample Academic Reading Module of IELTS and TOEFL as the post-tests. To determine whether there was any significant difference between the performances of the two intermediate groups, an independent sample T-test was administered to compare the means of the two groups in both posttests.

\section{Results}

4.1 Examining the normality of the distributions

Before commenting on the results of the analyses, the main assumption of independent samples T- tests namely, normality was examined. Skewness analysis was used to examine the normality of the distributions. The results of the skewness analysis revealed that the assumption of normality was observed in the distribution of the scores.

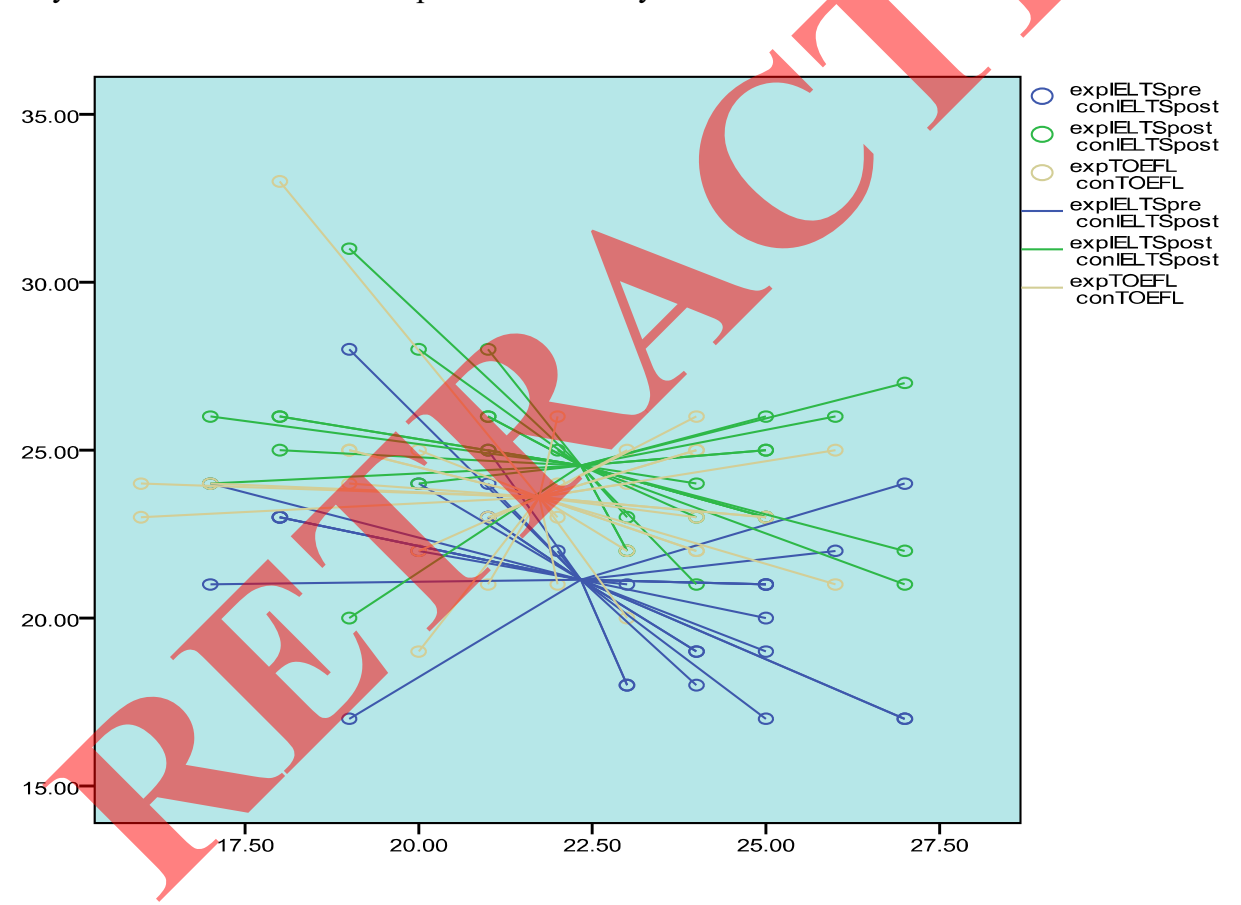

Figure 1. Scatter dot for the experimental and the control groups

\subsection{The homogeneity of the two groups at the beginning of the study}

After examining the normality of the distributions, an independent samples T-test was used to determine whether there was any significant different between the control group and the experimental in terms of their performance on pre- test IELTS at the beginning of the study. The results of the IELTS pre- test obtained by both the control and the experimental groups before the treatment phase indicated that there was not a significant difference between the mean scores of the two groups in IELTS pre-test at the 0.05 level $(\mathrm{P}=0.80)$. The experimental group (A) with mean score of 21.13 , and the control group with total mean score of 21.30 , had similar performance on IELTS pre- test. In other words the two groups were homogeneous in terms of their performance on IELTS at the beginning of the study. 


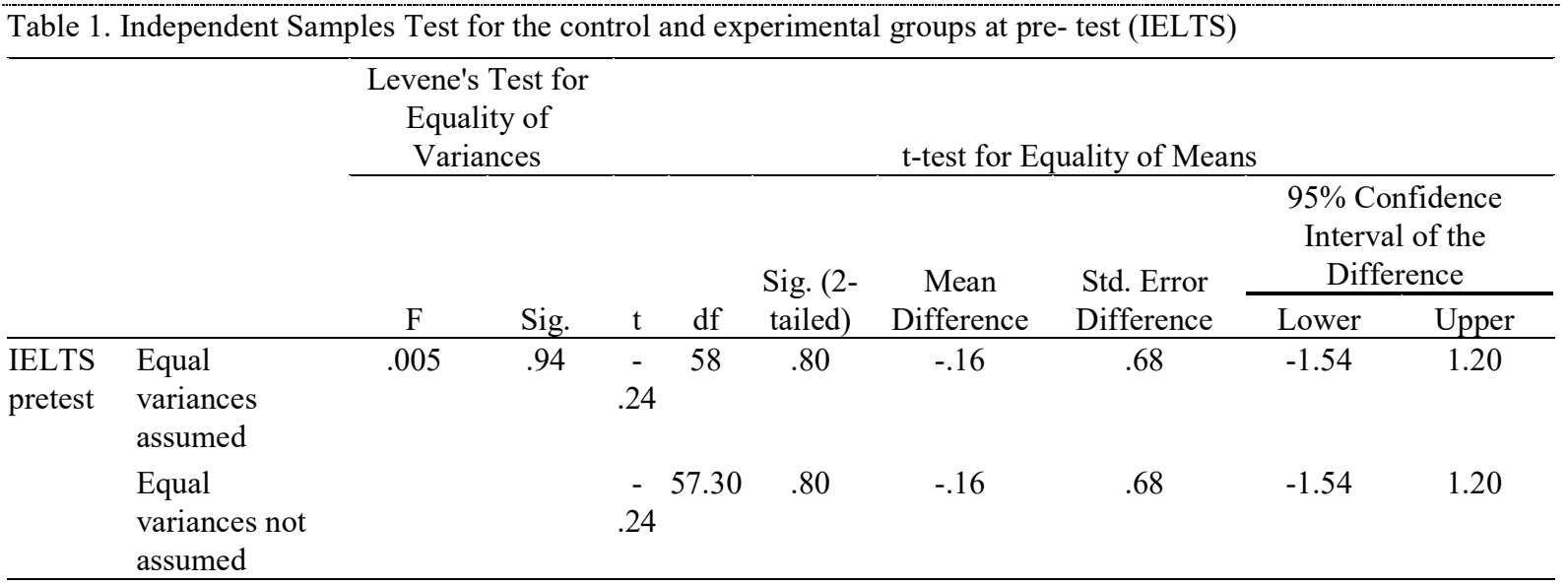

\subsection{The first research question: (Descriptive statistics for the IELTS post-test scores)}

Another independent samples $\mathrm{T}$-test was run to determine whether there was any signifieant difference between the control and the experimental groups after the treatment phase. The experimental group (A) with total mean score of 24.53 , comparing to 22.33 for the control group had a better performance on IELTS post- test.

Table 2. Independent Samples Test for the control and experimental groups at post- test

\begin{tabular}{|c|c|c|c|c|c|c|c|c|}
\hline & & $\begin{array}{r}\text { Levene } \\
\text { Equ } \\
\mathrm{Var}\end{array}$ & $\begin{array}{l}\text { est for } \\
\text { of } \\
\text { es }\end{array}$ & & $l=$ & & & \\
\hline & & & & & Sig. (2- & Std. Error & $\begin{array}{r}95 \% \mathrm{C} \\
\text { Inter } \\
\text { Dif }\end{array}$ & $\begin{array}{l}\text { idence } \\
\text { of the } \\
\text { nce }\end{array}$ \\
\hline & & $\mathrm{F}$ & Sig. & $\mathrm{t}$ & df tailed) Difference & Difference & Lower & Upper \\
\hline $\begin{array}{l}\text { IELTS } \\
\text { post-test }\end{array}$ & $\begin{array}{l}\text { Equal } \\
\text { variances } \\
\text { assumed }\end{array}$ & 4.734 & .034 & 3.05 & $58 \quad .003$ - 2.20 & .71 & .76 & 3.63 \\
\hline & $\begin{array}{l}\text { Equal } \\
\text { variances not } \\
\text { assumed }\end{array}$ & & & & 2.20 & .71 & .75 & 3.64 \\
\hline
\end{tabular}

The results of the independent samples T-test rejects the first null hypothesis as there is no significant difference between the experimental group who received instruction on test taking strategies and the control group who did not receive specific training on test taking strategies in terms of their performance on international English language tests (IELTS).

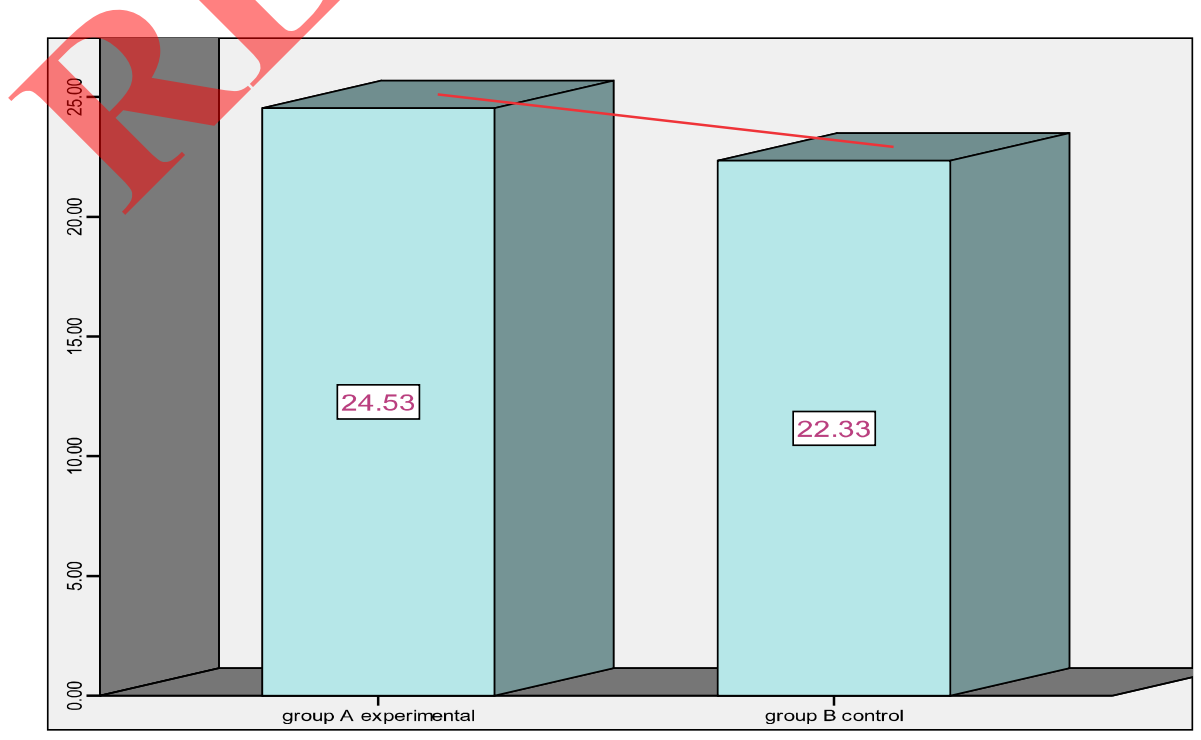

Figure 2. The mean scores of the control and experimental groups at IELTS post- test 
4.4 The Second Research Question (Descriptive statistics for the TOEFL scores)

In order to examine the possible difference between the control and experimental groups in terms of their performance on TOEFL test, another independent samples T- test was run to the results of the TOEFL test. The findings indicate that the experimental group $(X=23.60)$ who received special instruction in terms of test taking strategies outperformed the control group $(X=21.73)$ in TOEFL test.

Table 3. Independent Samples Test for the control and experimental groups at TOEFL post- test

\section{Levene's Test for \\ Equality of \\ Variances}

t-test for Equality of Means

$95 \%$ Confidence

Interval of the

\begin{tabular}{|c|c|c|c|c|c|c|c|c|c|c|}
\hline & & \multirow[b]{2}{*}{$\mathrm{F}$} & \multirow[b]{2}{*}{ Sig. } & \multirow[b]{2}{*}{$\mathrm{t}$} & \multirow[b]{2}{*}{$\mathrm{df}$} & \multirow{2}{*}{$\begin{array}{l}\text { Sig. (2- } \\
\text { tailed) }\end{array}$} & \multirow{2}{*}{$\begin{array}{c}\text { Mean } \\
\text { Difference }\end{array}$} & \multirow{2}{*}{$\begin{array}{c}\text { Std. Error } \\
\text { Difference }\end{array}$} & \multicolumn{2}{|c|}{ Difference } \\
\hline & & & & & & & & & Lower & Upper \\
\hline TOEFEL & Equal & 1.87 & .17 & 2.71 & 58 & .009 & 1.86 & .68 & .49 & 3.24 \\
\hline
\end{tabular}

reading test variances assumed

Equal

The data in table 3 indicates that there is a significant difference between the mean scores of the control and the experimental groups at the .05 level at TOEFL test. This analysis shows that the subjects in the experimental group again achieved higher scores than those in the control group. The findings further reject the second null hypothesis as there is no significant difference between the experimental group who received instruction on test taking strategies and the control group who did not receive specific training on test taking strategies in terms of their performance on TOEFL test.

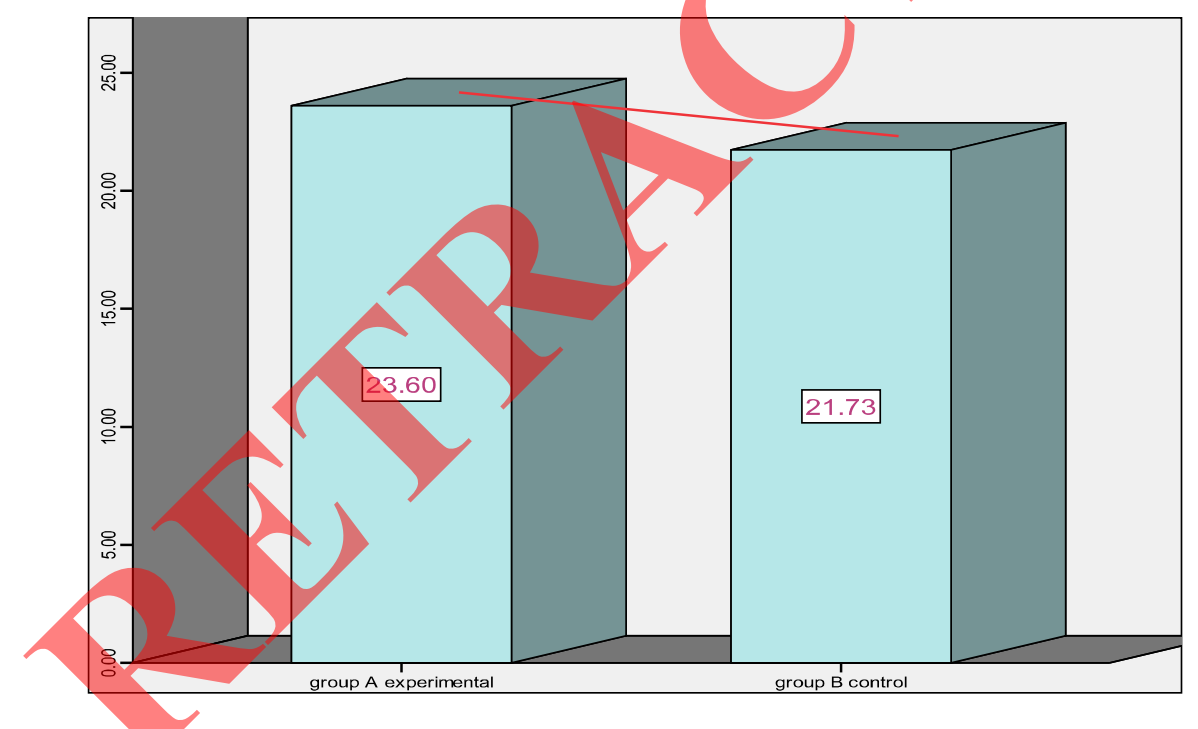

Figure 3. The mean scores of the control and experimental groups at TOEFL post- test

\section{Discussion and Conclusion}

This study supported a strong relationship between a successful performance on reading comprehension tests and employing test taking strategies. The results of the present study support the findings of other similar studies that have probed the impacts of test-taking strategies on test performance (e.g., Cohen, 1984; Nevo, 1989; Phakiti, 2008; Radojevic, 2009; Rezaee, 2005). They all supported that "performance on language tests can be improved by test taking strategies."

It can be concluded that integrating test taking strategies in teaching curriculum could be profitable for the students. The awareness of strategy instruction, using presentation and modeling of strategies, helps learners to benefit from test taking strategies and employ them effectively (Alderson, 2000). English teachers should teach test-taking strategies and take the role of motivators. Test designers may use the results of this study to develop better tests. The role of test taking strategies should be stressed in Iranian EFL situation because it appears to be a neglected area. A repeat study could be conducted with other levels with different background knowledge and in different fields of study, or with high school students. This study could be carried out again allowing time for more practicing of test taking strategies. And finally, further study could encompass the teaching of test-taking strategies for other English skills and other test formats, such as listening tests, writing tests, matching tests, true-false tests and essay tests. 


\section{References}

Aldersron, J. C. (2000). Assessing reading. Cambridge: Cambridge University Press

Cohen, A. D. (1984). On taking language tests: What the students report. Language Testing, 1, 70-81.

Nevo, N. (1989). Test-taking strategies on multiple-choice test of reading comprehension. Language Testing, 6(2), 199215.

Nunan, D. (1999). Second language teaching and learning. Boston, M. A.: Heinle Heinle.

Phakiti, A. (2008). Constructed validation of Bachman and Palmer's (1996) strategic competence model over time in EFL reading tests. Language Testing, 25(2), pp. 237-272.

Radojevic, N. (2009). Exploring the use of effective learning strategies to increase students' reading comprehension and test taking skills. Unpublished Master, Brock University, St. Catharines, Ontario.

Rezaei, A. (2005). Test-taking strategies and performance in language achievement tests. Pazhuhesh-e Zabanha-ye Khareji, (20), 27-50.

Rezaee, A. A. (2006). University students' test-taking strategies and their language proficiency. TELLSI, 1(1), $151-182$.

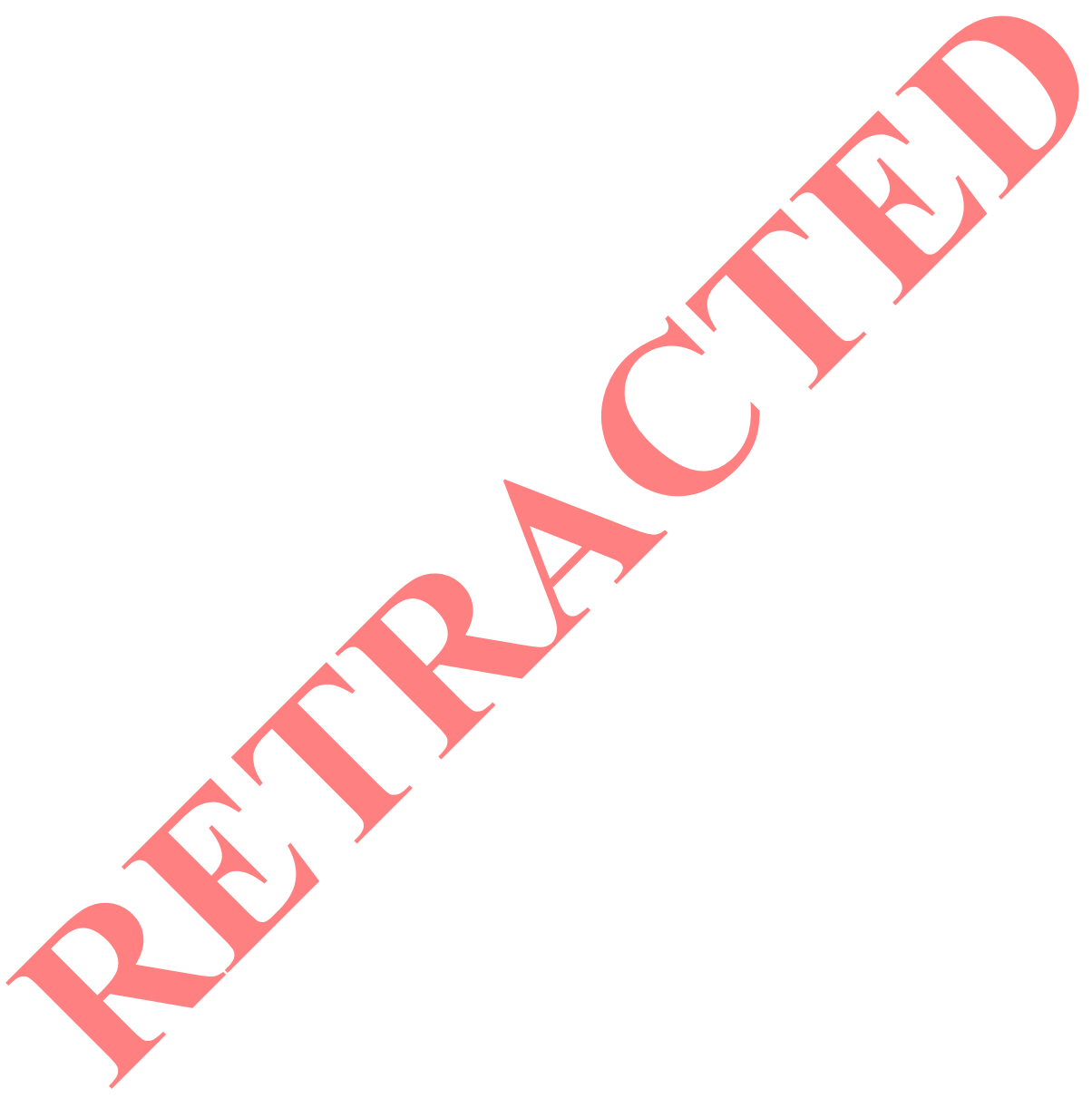

